\title{
Os concursos para a carreira acadêmica
}

\author{
Alice Reis Rosa (*)
}

Percebemos bem isso, quando, em qualquer de nossos atos, por um acontecimento infeliz, (...) nos damos conta de não estarmos por inteiro naquele ato e que seria, portanto, uma injustiça atroz julgar-nos só por isso ... durante uma existência inteira, como se toda ela se resumisse naquele ato!

\section{Pirandello (1)}

Na Faculdade de Medicina da UFRJ, no periodo de 1974 a 1978 , realizaram-se 106 concursos, dos quais 70 para preenchimento de vagas nas três categorias do Grupo Magistério, e 36 para a docência livre. (2)

Acompanhamos vários desses concursos que, enquanto se fazem, modificam a atmosfera do trabalho cotidiano, pela idéia de renovação que trazem implicita, pelo estimulo à emulação em nivel elevado, pela alegria dos resultados justos e compensadores. Em sua observação atenta, entretanto, identificam-se alguns pontos que estão merecendo trabalho de revisăo. Mantêm-se práticas tradicionais, que não aproveitam o moderno instrumental existente no campo da medida e avaliação educacionais.

A seleção, ou promoção de professores, através da prestação de concurso,

* Diretora Adjunta para Ensino de Graduação da Faculdade de Medicina da UFRJ. tem o inconveniente de apoiar-se, apenas, em amostras sumárias e, por vezes, não representativas do desempenho docente. "Se é verdade que muitas vezes os melhor dotados acabam por sobressair, também é fato que numerosas qualidades jamais conseguem vencer barreiras do ambiente (quando não do próprio individuo." (3) A diversidade das provas e, em particular, o exame dos títulos do candidato, mecanismos utilizados para reduzir o inconveniente apontado, não são suficientes.

Esse tipo de seleção repousa, somente, na aferição dos conhecimentos e habilidades presentes. "Em vez de julgar os aspirantes ao cargo, como de hábito, somente pelo que já sabem, será melhor descobrir os que mais prometem." (4) Uma das distorções do processo vigente é não incluir a medida de atitudes dos candidatos. Atitudes não só relativas às funções da universidade, aos propósitos da educação superior, ao papel do professor universitário etc., mas, também, aquelas demonstradas na atividade diária, tais como, relacionamento interpessoal, espírito de colaboração, iniciativa, rendimento do trabalho, zelo institucional. Não se desconhecem, todavia, os múltiplos obstáculos inerentes a esse tipo de avaliação: necessidade de técnicos para seleção e construção dos instrumentos adequados, tempo, custo, erros de 
julgamento, variedade de procedência dos candidatos, entre outros.

Enquanto se mantêm os concursos, apoiados nos mesmos instrumentos tradicionais - exame de titulos, prova escrita, prova prática, prova didática, e de defesa de tese - por que não tentar introduzir modificações, objetivando não apenas a melhor preparação de examinadores e candidatos, como, ainda, o rigor dos resultados e a redução do artificialismo do processo?

\section{PROGRAMAS DE CONCURSO}

Os programas de concurso são, geralmente, simples listagens de assuntos, não raro, desordenadas e calcadas no conteúdo programático das disciplinas do curso de graduação. Curiosa coincidência essa, porque, a despeito da forma e da profundidade com que a matériả pode ser diferentemente tratada, numa ou noutra situação, a seleção dos temas deve estar em conflito com critérios de relevância. O saber acadêmico, exigido do docente universitário não se superpõe ao saber prático, caracteristico do exercício da medicina, e para a qual devem ser preparados os alunos. Não podem coincidir, portanto, os programas. Basicamente, não se estabelecem critérios para selecionar e organizar os temas.

\section{EXAME DE TITULOS}

O Conselho de Coordenação do Centro de Ciências da Saúde da UFRJ, criteriosamente, aprovou normas para julgamento dos titulos, que foram classificados em quatro categorias, valorizadas com pesos diferentes, conforme o nivel para a qual se realiza o concurso: a) formação acadêmica; b) produção técnicocientifica; c) experiência didático-pedagógica; d) outros titulos. As categorias e a atribuição de pesos refletem definição acerca do que se espera dos docientes em diferentes estágios da carreira. Assim, a formação acadêmica adquire maior valor para o preenchimento de vagas de prolessores assistentes e adjuntos; a experiência didático-pedagógica tem maior peso, apenas, nos concursos para professor assistente. Dos candidatos a professor titular, exige-se maior produção técnico-cientifica.

Sem reduzir o valor da investigação científica, especialmente da que se aplica a nossa realidade, cabe perguntar se o modelo, inspirado no americano, por sua vez influenciado pelo alemão, é adequado, se não ao pais, pelo menos, ao momento. Sublinha-se a interdependência ensino/pesquisa. Não raro, entretanto, observa-se a dicotomia dessas atividades: professores dedicam-se à pesquisa, desvinculando-se do ensino, especialmente o de graduação. A tabela vigente legitima esse fato. A produção de conhecimentos será, de fato, atividade mais importante que a de formação de recursos humanos necessários ao desenvolvimento econômico-social? Quando a escola médica é tão criticada pela deformação e despreparo dos profissionais que produz, será adequado o estímulo ao afastamento dos mais experientes da prática de ensino? Em "A Carreira Acadêmica", diz o autor: "(...) fator que impede o ensino de ser uma carreira importante é que as faculdades e universidades, dedicadas, principalmente, a ensinar milhares de estudantes, obrigam seus professores a publicar. Uma situação parecida seria a do escritório de advocacia que produzisse artigos para as revistas de direito e negligenciasse os clientes". (4)

A importância dada à produção técnico-cientifica é tanto maior porque, em nenhuma das categorias, se valorizam a 
quantidade e a qualidade das ações de ensino e de assistência. A experiência didático-pedagógica que se aprecia, lamentavelmente, quase se restringe ao exercicio de cargos, ou funções no ensino superior e, de modo injustificado, distingue a experiência em nivel de pós-graduação. Essa é outra das várias distorções que desencorajam o compromisso didático-assistencial diário, fundamental para o ensino de graduação. Diz George Pickering: "( . . .) o ensino per se não recebe tais honras ou aclamações. O professor que dedica sua vida aos alunos tende a sentir que sai de cena sem ter sido glorificado". (5)

Quando será estimulado o compromisso dos professores com ensino de disciplinas instrumentais como, por exemplo, a Semiologia, e com a sólida formação ética e humanistica dos médicos de amanhã, capacitando-os a participar da transformação do sombrio panorama brasileiro de saúde? Quando serão contempladas as ações assistenciais prestadas pelos docentes?

Enquanto persistirem essas distorções, permanecerão a busca excessiva pela especialidade, a contestação à prática nos ambulatórios, o desinteresse pelas atividades educacionais e o refúgio no trabalho com os métodos especiais de diagnóstico e tratamento.

Uma nova tabela para apreciação dos titulos deveria tentar corrigir as falhas assinaladas, e. contemplar as várias opções permitidas, ou, até mesmo, exigidas pelo trabalho universitário. Hoje, nitidamente, distinguem-se docentes mais inclinados para atividades numa das äreas seguintes: pesquisa, ensino, assistência e administração. As normas atuais privilegiam, apenas, algumas dessas áreas, ou, mais restritivamente, funções nessas áreas, com a desvantagem de trazer implicito um modelo único a ser observado por todos os professores. É imperativo, portanto, criar um modelo abrangente, que contemple a totalidade das ações necessárias ao desenvolvimento da vida universitária e que não contrarie a tendência natural de maior dedicação a determinado setor de atividade.

\section{PROVA ESCRITA}

Falha, hoje, inadmissivel é resumir-se a prova escrita a uma questão que versa tema único. A prova, como instrumento de medida, deve colher amostra representativa do conhecimento de todo o programa, o que é incompativel com sua elaboração improvisada, no momento de instalação dos trabalhos da banca examinadora, com base no sorteio de pontos.

Outro aspecto a considerar é sua forma de correção - leitura pelo próprio candidato, ou pelos membros da banca, isoladamente. Uma e outra têm o inconveniente, já muito conhecido, da subjetividade do julgamento, sendo que na primeira, além da fragilidade da comparação dos candidatos, não se possibilita a revisão, pelo examinador, para mais apurada atribuição do grau.

Por que não seguir as normas para elaboração e correção de provas escritas clássicas, de tão fácil acesso na literatura especializada?

\section{PROVA DIDATTICA}

Nessa etapa, concentram-se distorções. Com antecedência de 24 a 48 horas, sorteia-se o ponto, e tem início verdadeira gincana. $\mathrm{O}$ candidato e seus amigos, velozmente, dão começo ao cumprimento das tarefas. Corre-se para os especialistas no assunto sorteado, para absorver sua experiência. Buscam-se patologistas, desenhistas e fotógrafos para a ilustração, às vezes desmedida, da 
aula. A casa do candidato é um ruidoso vaivém de colaboradores; o telefone soa continuamente; as opiniões se multiplicam, se entrechocam e confundem o candidato que, afinal, começa a ensaiar a aula. Hora avançada, repousa um pouco, para mais tarde comparecer, cansado e tenso, diante da banca. E ai tem inicio outra rotina: luz apagada e sucessão exagerada de diapositivos, em geral de fundo azul e letras brancas, em desrespeito à principal das recomendações para sua feitura: "Palavras não são recursos visuais"! (6) Piores os casos em que o candidato, pela primeira vez, usa o retroprojetor. Faz, normalmente, de forma errada e, não raro, embaraçosa. Modismo injustificado também é a distribuição de objetivos ao iniciar a aula, recurso em desacordo com o momento e, por isso mesmo, não utilizado pelo candidato, nem ao longo, nem ao final da exposição.

Todos conhecemos esses artificialis. mos. Por que perpetuá-los? Por que não estabelecer, claramente, os aspectos que estarão em julgamento?

A definição do que se espera dos candidatos permitirá orientá-los melhor, estabelecer o intervalo adequado entre o sorteio do ponto e a aula e, especialmente, fixar critérios para julgamento. Observa-se falta de consenso, até mesmo, acerca do nivel da aula: deve ajustar-se à graduação, ou à pós-graduação?

Curioso, entretanto, è o seguinte. vários dos últimos professores que se incorporaram à Congregação da Faculdade, além de intensa atividade no ensino, eram, reconhecidamente, excelentes didatas. Vale dizer, "passaram a vida dando aulas", num ambiente natural de interação professor-aluno, de comunicação de idéias, e com a responsabilidade de transmitir, corretamente, o conhecimento. Por que, para ser professor titular, foram julgados por um único desem- penho e em condições extraordinariamente artificiais?

\section{PROVA PRATICA}

Essa é a prova em que não há qualquer padronização das condições de medida: candidatos diferentes examinam doentes diferentes, interpretam métodos complementares diferentes, realizam cirurgias diferentes. A subjetividade do julgamento é máxima. E os resultados são contaminados por impressões, preconceitos e sentimentos.

Alèm disso, permanecem as criticas que se fizerem à prova didática. Que atributos querem verificar com essa prova? Por que julgar um único desempenho, quando, na maioria dos casos, a própria instituição legitimou a sucessão de desempenhos anteriores, quando estavam em risco a vida do doente e a aprendizagem do estudante?

\section{DEFESA DE TESE}

E a prova que se constitui em espetáculo. Por isso mesmo, não é raro ouvir-se de examinadores que a argüição se justifica pelo fato de dar ao candidato a "oportunidade de exibir seus conhecimentos". Ao longo da história da Faculdade, assinalam-se professores notabilizados pela excelência de suas argüições; registram-se momentos de argúcia e inteligência viva na defesa de candidatos. Contrariamente, apontam-se instantes de constrangimento. Os elogios, por exemplo, que se fazem examinador e examinado, cabem quando têm a elegância da discrição e, sobretudo, da sinceridade. Previamente construidos, forjados, desmedidos, têm o dom de constranger. Também, os examinadores se expõem, quando, ao interrogarem fora de sua competência especifica, e especialmente 
acerca da correção da linguagem e da metodologia do trabalho, chegam a considerar erros os acertos do candidato.

Mas, qual o objetivo dessa prova? Medir a qualidade do trabalho, da argumentação do candidato, ou de ambas? Se se medem ambas, por que, então, candidatos obtêm a nota máxima depois de sérias restrições à metodologia do trabalho?

\section{ATRIBUIÇÃO DE NOTAS}

Outro fator injustificável nos concursos são os graus conferidos. Distinguem. se, aprovam-se, reprovam-se candidatos por décimos, ou mesmo, centésimos de ponto. As provas, como instrumentos de medida, devem ser sensiveis às variações individuais. Será, entretanto, que são instrumentos tão aperfeiçoados que permitem verificar diferenças tão próximas? Em que se diferenciam desempenhos descritos por números tais como $8,90 \mathrm{e}$ 8,87 ? Por que candidatos recebem 7,01 e 9,9 ? O que permite conferir 9,3 e 9,1 a dois candidatos e, mais ainda, dizer que o primeiro está classificado, e o segundo não? As normas de concurso somente deveriam permitir fossem os graus atribuidos em números inteiros, na escala de 0 a 10 , o que, possivelmente, dificultaria a tarefa dos examinadores, porem, tornaria mais nitidos os resultados. "Dê notas, redondas, como $50,60,70,(\ldots)$ não perdendo tempo com frações, numa medida imprecisa por sua própria natureza. Diversos estudos sobre provas de resposta aberta já revelaram que as notas variam muito segundo a pessoa que as julga e também de acordo com o momento em que ela o faz. Notas fracionárias em tais provas não têm valor..." (7)
Esses comentários, embora na imperfeição da superficialidade, permitem entrever a fragilidade do mecanismo em que se apóiam a seleção e a promoção de professores universitários:

"Numa mesa redonda realizada na sede da UNESCO, sobre o papel e a função da universidade na sociedade moderna, os estudantes participantes concordaram em debater as questões suscitadas pela admissão de estudantes à universidade, mas com a condição de que fosse debatida, também, a questão da admissão de professores à universidade." (8)

O problema tem outras dimensões e complexidade. O que deve ser judiciosamente analisado é a composição do quadro do magistério superior. E isso implica autonomia universitária ... E não é tarefa para poucos, pelo risco de se limitar, como estes comentários, a reajustes nas práticas tradicionais.

\section{Referências Bibliográficas}

1. PIRANDELO, L. Seis personagens à procura de um autor. São Paulo, Abril Cultural, 1977.

2. FRAGA FILHO, Ciementino. Relatório final da Diretoria (quadriênio: setembro de 1974 à setembro de 1978), UFRJ, Faculdade de Medicina, 1978.

3. MEdEIROS, E. B. Principios e prática da medida psicológica. Rio de Janeiro, Fundação Getulio Vargas, 1976.

4. LIGHT, D. W. A carreira acadêmica. Diálogo, 6 (3):15-21, 1973

5. PICKERING, G. O Desafio à educação. Rio de Janeiro, Zahar, 1972.

6. JAY, A. Apresentação eficiente. Rio de Janeiro, Fundação Getulio Vargas, 1973.

7. MEDEIROS, E. B. Provas objetivas. $4^{\text {? }}$ ed. Rio de Janeiro, Fundação Getulio Vargas, 1975.

8. NAJMAN, D. Professores de que e para quê? $O$ CORREIO DA UNESCO. (8), ago. 1975. 